\title{
Big Is Beautiful: Illinois Wins Exemplary Program Award
}

\author{
Allyn Jackson
}

Eighty thousand credit hours. Twenty-six thousand student classes. Twelve hundred math majors, two hundred twenty-five graduate students, seventy tenure-stream faculty, and twenty postdocs. These numbers capture one aspect of the mathematics department at the University of Illinois at Urbana-Champaign: It is big. The department has faced all the challenges typical in departments of its kind, including shrinking resources, pressure from other departments over math requirements, steep increases in undergraduate enrollments, and heightened expectations for teaching quality.

Far from tottering under the weight of these responsibilities, Illinois has thrived. The department's large size brings a wealth of expertise and creativity to bear on the challenges it faces. The faculty have set in motion innovations that have increased the quality of the education it delivers at all levels, stimulating the enthusiasm of both students and faculty. Long a successful department, Illinois has become one that is truly outstanding. For these achievements, the mathematics department at the University of Illinois has received the AMS Award for an Exemplary Program or Achievement in a Mathematics Department.

\section{An Influential Department}

Neither an Ivy Leaguer nor a member of the coastal elite, the University of Illinois at Urbana-Champaign nevertheless possesses a mathematics department that has long been prominent on the mathematical scene. The department's large size allows it to maintain research strength

Allyn Jackson is senior writer and deputy editor of the Notices. Her e-mail address is axj@ams.org.

For permission to reprint this article, please contact: reprint-permission@ams.org.

DOI: http://dx.doi.org/10.1090/noti1526 across all areas of mathematics. A list of the research publications of the math faculty during 2010-15 runs to sixty-six pages and contains over one thousand entries. A major PhD producer, the department in recent decades has turned out between 1.5 percent and 2 percent of all math doctorates in the nation. The department publishes a journal, the Illinois Journal of Mathematics, founded in 1957 by Illinois mathematicians Reinhold Baer and Joseph L. Doob, along with Abraham Taub, George Whitehead, and Oscar Zariski.

Another way to gauge the department's influence is through its extensive service to the mathematical community. Two Illinois mathematicians served as AMS president: Doob (1963-64) and Arthur Byron Coble (1933-34). Robert M. Fossum served as AMS secretary from 1989 to 1999 and might hold the record for serving on the largest number of AMS committees (the current AMS secretary, Carla Savage, got her PhD at Illinois). Philippe Tondeur served as director of the Division of Mathematical Sciences of the National Science Foundation (NSF) from 1999 until 2002, a period in which math was named an NSF "priority area" and received double-digit increases.

Yet another example is Paul T. Bateman, a largerthan-life figure with outsize energy and enthusiasm who served as AMS associate secretary and was on the Board of Trustees. He joined the Illinois faculty in 1950 and remained active through his retirement in 1989 and until his death in 2012. Bateman built up the department in ways big and small, raising its research profile, hosting annual grill parties, and organizing a softball team known as the P. T. Batsmen. From 1965 to 1980 he served as head and presided over a dramatic expansion of the department.

In the 1990s, as faculty hired during the Bateman era began to retire, the department hired several new faculty per year for several years running. Not seeking to reproduce its past research strengths, the department 


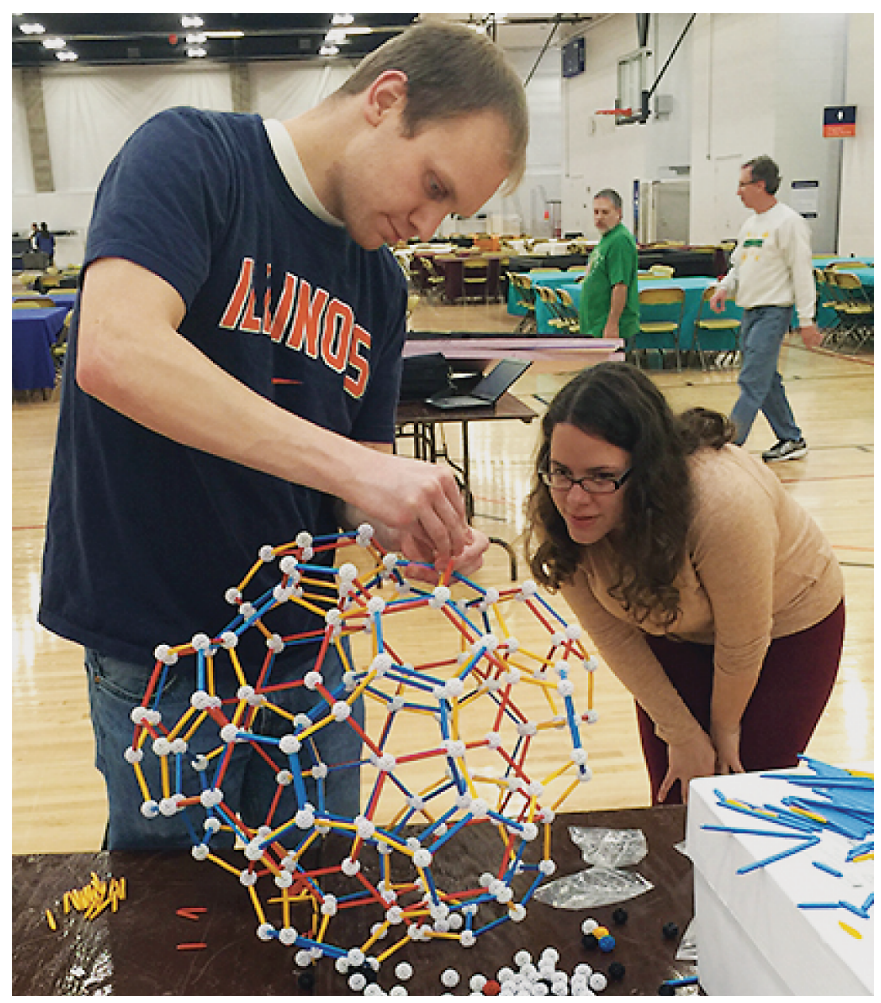

Illinois Geometry Lab volunteers Matthew Romney and Vanessa Rivera Quiñones creating materials for outreach work.

instead focused simply on getting outstanding mathematicians. Many of the people hired in that period have now emerged as leaders in the department's recent achievements. They have capitalized on the longstanding traditions and experience at Illinois to bring the department's functions to a new level of excellence.

\section{Responding to Shifting Student Needs}

Like many math departments across the country, Illinois has seen an increase in the number of math majors, though the increase at Illinois has been particularly sharp, up from 800 five years ago to 1,200 today. According to Randy McCarthy, director of undergraduate studies, this increase is not due to more students preparing for graduate school or for careers in secondary school. Rather, it has been fueled in large part by students who are doing "math plus," that is, a double major in mathematics plus another subject, such as computer science, engineering, or economics. Students value the addition of math for the insight it brings into the sophisticated modeling and statistical tools that are pervasive in quantitative areas. Also, the 2008 financial crisis raised uncertainties about job prospects after college. Students used to be able to count on good grades leading to a good job, McCarthy said. "Nowadays, they are much less confident they are going to get that job, and they are looking for an edge. They feel math gives them a competitive edge."

The Illinois department has excelled in responding to such shifts in the needs and expectations of its students.
One innovation in this direction is the Illinois Geometry Lab (IGL). The IGL was founded by Jayadev Athreya, who has since moved to the University of Washington (where he has opened a similar lab); currently the director is Jeremy Tyson. The IGL offers undergraduates the opportunity to work on semester-long projects under the guidance of faculty. Not all of the projects are in geometry, and many focus on applications of mathematics to other subjects, but they all have a large computational component. Topics have ranged from modeling taxi routes in New York City, to studying properties of knots with a large number of crossings, to solving problems related to lithium-ion battery design, to investigating randomness in number theory. The students learn what it's like to work on a team and struggle with open-ended problems. This builds communication skills, as do the end-of-semester talks the students present before the entire lab.

The IGL has a second purpose: to showcase mathematics to the general public and to $\mathrm{K}-12$ students. The lab conducts about twenty-five public outreach activities each year, which have IGL students toting the lab's 3-D printer to places like farmers' markets and schools. There are also events in which K-12 students visit the IGL. Reaching thousands of people, these events have stoked enthusiasm for mathematics among the general public-and among the IGL students. "The students who get involved in IGL projects are interested in doing collaborative, interactive things," said department chair Matthew Ando. "They have a lot of energy, and they like to communicate about mathematics. It's turned out to be a very strong community for outreach." Currently about sixty undergraduates participate in IGL projects. With funding from NSF and from donors, the department plans to increase this number by supporting more postdocs who can initiate IGL projects.

Another departmental innovation began around ten years ago, when complaints came from the engineering school about calculus classes. One of the complaints was an oft-heard one: engineering students need a calculus class that specifically prepares them for engineering applications. Another was that many engineering students with good scores on the AP Calculus BC Exam did poorly when placed directly into multivariable calculus. The math department collaborated with the engineering school to develop a new course, team-taught by mathematicians and engineers. Together they developed problem sets based on science and engineering applications, which students work on in teams in active-learning mode during discussion sections. They also strategically reorganized the syllabus so that the course covers the traditional Calculus 1 and The students
"feel math
gives them a
competitive
edge." Calculus 2 in a single semester. And instead of easing students in with familiar material, the course starts off with Taylor series. "So we disrupt their idea that they know the material really well," Ando said. "That gets their attention!" 


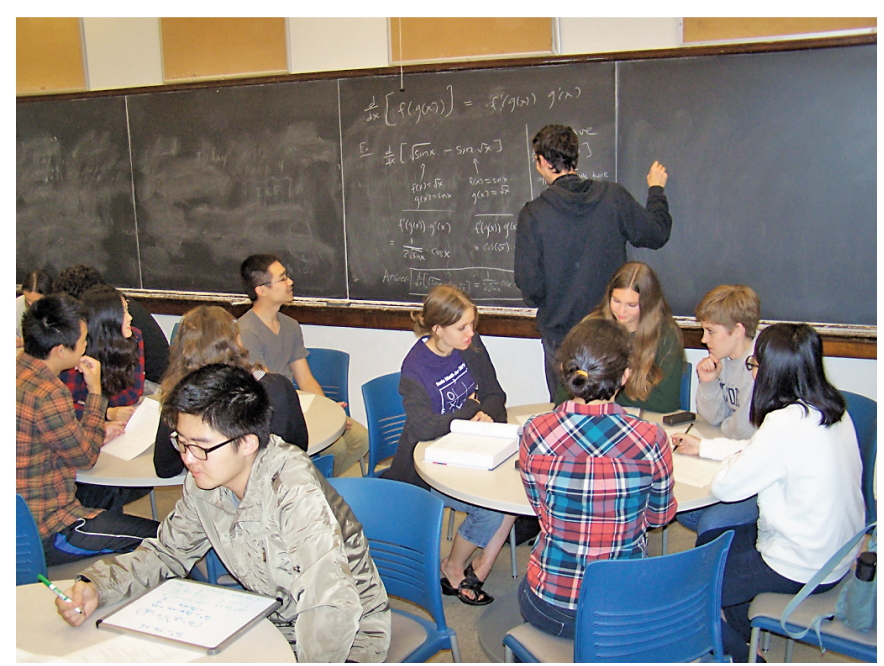

An active-learning classroom in action.

"We learned a lot from developing and teaching that course," Ando continued. "And then this marvelous thing happened." As faculty rotated through the course, they became "infected" by the active-learning model. This model had actually been used for twenty-five years in the department's Merit Program for Emerging Scholars. Based on the ideas of Uri Treisman, the program recruits students who have strong academic records and come from traditionally "un-

Faculty became "infected" by the active-learning model. derserved" populations, which include minority groups underrepresented in mathematics as well as first-generation college students. Merit students attend regular lectures, but instead of traditional one-hour discussion sections, they participate in two-hour "workshops" in which they collaborate on problem sets.

The success of the Merit students and of those in the new engineering calculus class got the department to thinking. "People realized that the active-learning model of the engineering calculus course would work in other larger courses," recalled associate chair Scott Ahlgren. Around this same time, climbing student enrollments and budget constraints led the department to consolidate its approximately 100 calculus classes, which had around 30-35 students apiece, into large lecture classes with 30-student discussion sections. The sections are conducted entirely in active-learning mode, with groups of 4 students collaborating on problem sets as TAs circulate around, giving hints and encouraging students to talk to each other. All students have a stake in participating: Everyone must write up a solution set, but from each group only one set, chosen at random, will be graded.

After ten years of patient work on large-lecture calculus, the courses are working smoothly and efficiently. In that time, the department's total teaching load went from 20,000 student-courses a year to 26,000 today. So the department has begun extending the large-lecture model to other courses, such as linear algebra. The faculty remain wistful about the loss of small classes but have found that the large-lecture model brings some unexpected advantages. In the days of the small calculus classes, "You would just pick up your book and go teach," Ando said. "Thirty students-what could go wrong?" With the large-lecture courses taught by two or three faculty, "we learned how to collaborate with each other." When someone who has not taught the course before comes in to teach it, he or she learns the ropes from colleagues and inherits a wealth of experience. "We have a lot materials, we have videos, a bunch of worksheets, and instructions for TAs on how to run the sections," Ahlgren said. "We can pass on the knowledge of how to run this operation. This process has grown organically." Ahlgren also noted that the collaboration has brought greater consistency to the courses.

In addition to providing a model for improving its largelecture classes, the collaboration with the engineering school has changed how the math department is perceived on campus. Richard Laugesen, the department's director of graduate studies, said that twenty years ago engineering faculty members would often grumble that the mathematicians weren't interested in applied topics and paid no attention to the needs of engineering students. "We don't hear any of that now," Laugesen remarked. "They understand that we are engaged and we want to work with them to find solutions for their students."

The department meets needs of students in many other ways. Its Actuarial Science Program enrolls almost 400 undergraduate majors and is growing at the graduate level to address increasing demand in risk management. The department also has a distance-learning program called NetMath, founded twenty-five years ago by Debra Woods and the late Jerry Uhl, which provides opportunities for high school students and nontraditional students. Most recently, NetMath has offered summer courses for Illinois undergraduates.

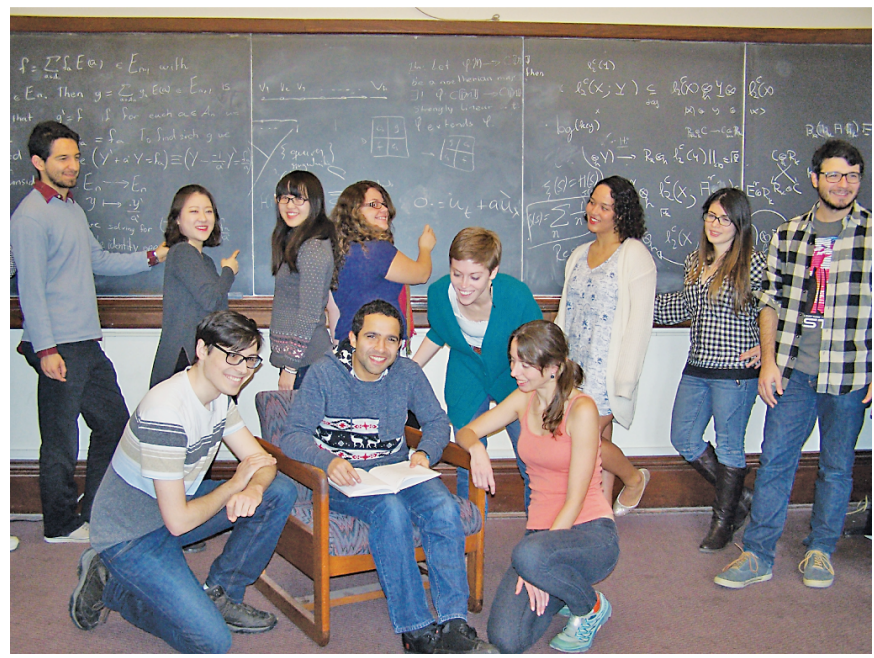

Graduate students relaxing in the common room. 


\section{"We Want You to Succeed"}

Melinda Lanius majored in math at Wellesley College and had no idea what area she might specialize in when she joined the PhD program at Illinois. Halfway around the world, Caglar Uyanik did his undergraduate work at Middle East Technical University in Ankara, Turkey, one of that nation's premier public research universities. He wanted to do geometric group theory and decided on Illinois for graduate school because of its strength in that area. These two

The PhD program is "very streamlined." very different students, with very different starting points, are now close to finishing their PhDs. Both thrived in the Illinois department. Uyanik spoke of the friendliness of both the graduate students and the faculty, noting that there is "more solidarity than competition" among the students. Lanius said, "You can figure out what type of mathematician you want to be while at Illinois, and then there is a ton of support to help you prepare for and realize that choice."

Serving well the broad range of graduate students who enter the $\mathrm{PhD}$ program is a major focus at Illinois. Attrition is low; if the department recruits twenty-five new students in the doctoral program, said Laugesen, usually twenty-four are back the second year. "That's a reason we tell students, 'Come to Illinois. We are investing in you, and we want you to succeed."' In recent years, the department has worked hard to increase diversity in its graduate student population. Today the graduate student body is 38 percent women, up from about 25 percent a decade ago. "That's something that we feel has really changed the tone of the PhD program," Laugesen noted. The department's Association for Women in Mathematics (AWM) chapter, founded in 2011, runs a host of activities that are open to all students and that have deepened the sense of community in the department. Through tireless recruiting at events like SACNAS meetings and the Field of Dreams conferences, the department has also increased the number of students from minorities underrepresented in mathematics, who now account for 22 percent of the US citizens in the $\mathrm{PhD}$ program.

The program is "very streamlined," Laugesen said. Instead of a qualifying or comprehensive examination that students must pass early on, the program requires satisfactory grades in basic coursework in the first year and a half. One required course is Math 499, which is essentially a seminar in which faculty members give informal talks about their areas of research to help students get oriented toward choosing an advisor. The foreign language requirement, which was a hindrance to some students, has been eliminated. The department has developed a timetable that spells out the milestones toward the degree and when a student should reach them. By the end of the second year, students are expected to have found an advisor and have begun working on a thesis proposal. "This all helps emphasize that it is a research-focused degree," Laugesen said. "The courses are a foundation to help them figure out what they want to do. But the emphasis is on getting them connected with an advisor and getting them into research."

Each fall Laugesen meets with every single doctoral student-all 160 of them-to monitor their progress and help them clear obstacles they may have encountered. In the spring, each student must present a formal progress report. "It's remarkable the effect [the timetable] has," Laugesen said. "When there is no goal or requirement or deadline, then a lot of people will drift. When they know what they have to accomplish, they tend to get it done." Through the systematic use of the timetable, the department has seen the time-to-degree decrease.

One of the biggest innovations the department has made is to give students opportunities that prepare them for careers outside academia. With funding from the NSF, the department created PI4 (Program for Interdisciplinary and Industrial Internships at Illinois), which provides training and internships for $\mathrm{PhD}$ students. The program

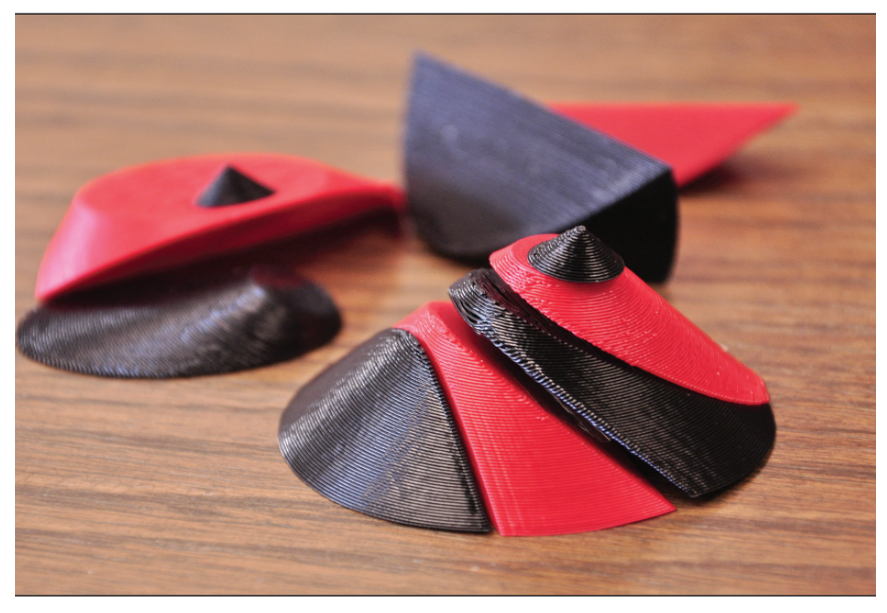

Using the Illinois Geometry Lab's 3-D printer, undergraduate student Hiroshi Fuii designed and printed colorful plastic models to illustrate how circles, ellipses, hyperbolas, and parabolas arise as conic sections. When stacked together the pieces of the model form a cone. The cross sections revealed by the slices range through the full set of "conic sections." Faculty member Steven Bradlow used the models in a course on curves that he taught at the African Institute of Mathematical Sciences in January 2013.

includes a "Summer Computational Boot Camp" in which students pick up programming skills. They are then placed in internships in companies or laboratories or in other departments on the Illinois campus where mathematical thinking can make a contribution to research. The number of summer internships has grown from six in 2013 to a total of thirty-one in 2016. The internships do not slow the progress towards the PhD. "In fact, quite the reverse," Laugesen noted. "Students who aim at an industry career tend to finish a little quicker because they are very motivated." 
Laugesen and two of his colleagues, Yuliy Baryshnikov and Lee DeVille, described the PI4 program in an article that appeared in the March 2017 issue of the Notices (https://tinyur1.com/bardev1au). The article notes that currently around 1,900 mathematical sciences PhDs are produced every year in the United States, while each year only about 1,000 tenure-track positions are under recruitment. Inevitably, many new PhDs seek employment outside academia, but mathematics faculty do not always have relevant experience to guide them. "There are ways in which mathematics is useful in the world that twenty or twenty-five years ago, when I was in graduate school, we just never would have imagined," Laugesen said. Programs like PI4 provide a model that other departments can use to better prepare their graduate students for the many new opportunities that are opening up outside academia.

\section{A Healthy and Mature Department}

Like many math departments at state institutions, Illinois operates under considerable budget pressure and uncertainty. But the faculty has been entrepreneurial in seeking support for the many things they do. In addition to grants for programs like PI4, more than half of the faculty hold individual or small-group research grants. The department is the hub of a large research network called GEAR (GEometric structures And Representation varieties), led by Steve Bradlow and supported by a US $\$ 2.5$-million NSF grant. NetMath contributes to the department in many ways, for example, by supporting teaching assistantships and fellowships for graduate students, as well as research experiences for undergraduate students. Donors support a variety of programs, such as lecture series, scholarships, and named professorships.

The drive and enthusiasm of the faculty rub off on the students. For example, Lanius and other students created a summer math camp for high school students, now held

\section{preparing students for careers outside academia} annually on the Illinois campus. She has served as an officer in the department's AWM chapter, organizing social events for the entire mathematics graduate student population that help students to bond and support each other during the year. The chapter also has its own colloquium series, with talks accessible to first- and second-year graduate students, and offers professional development workshops on topics like creating a website and how to give an "elevator pitch." Last fall the AWM chapter officers came to Ando with a list of several activities that they hoped the department would fund. "They have such initiative," Ando remarked. "We are not a wealthy department, but if somebody comes to ask for funds for such worthy activities, you turn around and find the money." To capitalize on the enthusiasm of the undergraduate majors, the department has created "Mathematics Ambassadors," a program that each year designates around twenty math majors who exemplify academic strength, leadership

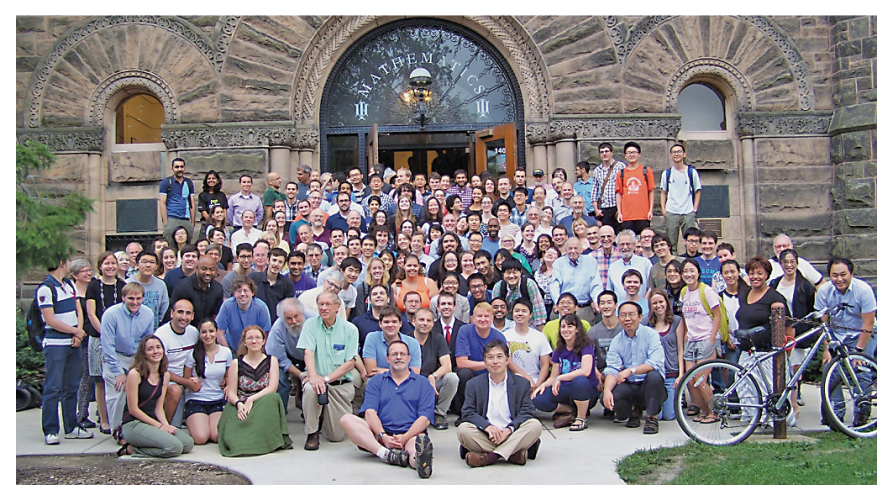

Students, faculty, and staff gathered in front of Altgeld Hall, home of the Illinois mathematics department.

ability, and commitment to the department. The ambassadors participate in outreach events and act as an advisory group for the undergraduate program.

What is the secret to the department's success? "We have a particularly healthy and mature department," McCarthy said. "We don't have a lot of turf wars or people arguing among each other." The faculty members place a strong emphasis on research but at the same time are very student oriented. Many of them have received teaching awards (as have many graduate students serving as TAs). The faculty's shared commitment to students serves to shift discussions away from narrow self-interest and toward the question, What is best for the students? That the department is so big reinforces the shared focus on students. "We have such a critical mass, we are so large, that once you have that attitude, it tends to be self-stabilizing," said McCarthy. Even when faculty members go through an upheaval, it doesn't last long because everyone remembers the pleasant steady-state environment that usually prevails. "There is a strong desire to return back to that healthy norm," McCarthy said.

As big as the Illinois department is, Ando believes the AMS award his department has received actually reflects the achievements of an even bigger group. Having served as chair for five years, he has visited many other departments doing similar things. "There are great things going on in mathematics departments across the country," he said. "I hope that this award will help draw attention to the efforts and achievements of the whole mathematics community."

\section{Photo Credits}

Photo of colorful plastic models is courtesy of Laura Schaposnik. All remaining photos are courtesy of the Department of Mathematics at the University of Illinois at Urbana-Champaign. 